\title{
Regulating the monomer of polyhydroxyalkanoate from mixed microbial culture: with particular emphasis on substrate composition: A review
}

\author{
Tong Wei, Qian Fang ${ }^{\dagger}$ \\ Department of Municipal Engineering, College of Civil Engineering, Guangzhou University, Guangzhou, China
}

\begin{abstract}
Polyhydroxyalkanoate (PHA), produced by mixed microbial cultures (MMCs), is a biodegradable biopolyester that alleviates the global plastic crisis in the nearest future. Even PHA has become a research hotspot, reviews on PHA composition determining thermodynamic and processing properties of PHA products are rare. The primary focus of the evaluation relies on the factors affecting the PHA monomer composition of MMC-PHA production. Besides, since the volatile fatty acids (VFAs) composition of the substrates strongly influences the PHA monomer composition, regulating the ratio of even-carbon to odd-carbon VFAs, PHA, vary properties could be obtained predictably. So oriented acid production process, the first stage process in three-stage MMC-PHA production that can regulate the VFAs composition, is also comprehensively introduced to help understand PHA monomer regulation.
\end{abstract}

Keywords: Mixed microbial cultures, Monomer composition, Oriented acid production, Polyhydroxyalkanoate (PHA), Volatile fatty acids (VFAs)

\section{Introduction}

Polyhydroxyalkanoates (PHA), a kind of intracellular polyester that is environmental-friendly and can be degraded naturally, is produced by microorganisms under unbalanced external nutritional conditions (excess carbon source, lack of nutrient elements such as nitrogen and phosphorus) [1]. In a naturalistic setting, PHA is mainly a storage material for carbon sources and energy in organisms, and it is considered to be effective energy storage means for microorganisms to resist the environmental impact. After extraction and industrial processing, PHA products have similar material properties to traditional petrochemical plastics and can be used as biodegradable packaging materials, tissue engineering materials, medical materials, etc. [2]. Many microorganisms in nature contain PHA hydrolases, which can hydrolyze PHA into oligomers and monomers and use these products as the basis for bacterial growth. In recent years, with environmental concerns, PHA has attracted significant attention due to its complete biodegradability. At the same time, PHA is also widely considered a potential replacement for traditional petrochemical plastics, and it is hoped to alle- viate the current pollution crisis of plastics [3].

Currently, there are two main methods to produce PHA from bacteria. One is the pure culture mode, the main mode of commercial and industrial-scale production. Single strain or engineering bacteria with good PHA synthesis ability is used to produce PHA. However, the pure culture mode needs strict aseptic environment conditions and high-purity carbon source substrate, making the production cost of PHA products still at a high level. The high production cost has dramatically reduced the economic competitiveness of PHA compared with traditional petrochemical plastics and limits the wide application of PHA products [1]. The other method is using mixed microbial communities (MMCs) as the biological carrier for PHA synthesis. In the pure culture mode, fermentation facilities, operating environment and substrates need to be sterilized strictly to prevent other hybrid bacteria, which would destroy the PHA production capacity, from adulterating into pure cultured microorganisms. While compared with the pure culture mode, the MMC-PHA production mode has richer microbial diversity to resist the environmental impact, so PHA synthesis can be carried out in a more open environment. Detailly, the MMC-PHA
This is an Open Access article distributed under the terms of the Creative Commons Attribution Non-Commercial License (http://creativecommons.org/licenses/by-nc/3.0/) which permits unrestricted non-commercial use, distribution, and reproduction in any medium, provided the original work is properly cited.

Copyright (C) 2022 Korean Society of Environmental Engineers
Received July 15, 2021 Accepted September 14, 2021

${ }^{\dagger}$ Corresponding author

E-mail: 263438517@qq.com

Tel: +86-020-13660263976

ORCID: 0000-0001-8672-8200 
production process does not require strict substrate sterilization or an aseptic operation environment, which avoids the high energy cost [1]. Besides, low value and easily available organic wastes, such as volatile fatty acids (VFAs), crude glycerol, etc., were usually used as carbon source substrates in MMC-PHA production. Hence MMC-PHA production mode is cheaper, more environmentally-friendly, and more sustainable and it is a hot research topic for biopolymer scientists at present and even in the future.

In addition to the similar Physico-chemical performances, such as corrosion resistance, to those of traditional petrochemical plastics, the bioplastic products made from PHA also have complete biodegradability, excellent biocompatibility, and so on. The biopolymer researchers have found that the PHA's thermal and mechanical properties can be regulated by controlling its monomer composition [4]. Furthermore, the PHA's monomer composition has a great relationship with the degradation rate under various environmental conditions [5]. In the past 20 years, many reviews have summarized and analyzed how to improve PHA content in MMCs, but the articles reviewing PHA composition in MMCs are rare. Therefore, this work attempts to provide an outline of the current research relative to PHA's monomer composition adjustment from MMC-PHA production and their processing conditions for the regulation of PHA performance in MMC-PHA production.

\section{The Structure and Properties of PHA}

The first kind of PHA, polyhydroxybutyrate (PHB), was first identified and discovered by Lemoigne from Bacillus Megaterium in the early 20th century [6]. During the 1960s and 1990s, researchers gradually found more types of PHA [7-9]. Compared with traditional fossil plastics, different kinds of PHA have great differences in structure and properties, which provides unlimited possibilities for the processing properties of bioplastics. According to the report, PHA has unique biodegradability, biocompatibility, controllable thermal processing properties, and other mechanical properties similar to traditional petrochemical plastics [10]. The diversity of its properties is mainly affected by the monomer type, monomer proportion, and molecular weight of PHA [11].

Structurally, PHA is a linear polyester composed of ester linkage linking hydroxyalkanoates (HA) monomers. The general formula of PHA is shown in Fig. 1. In the formula, $n$ represents the amount of HA in the polymer chain, which varies from 100 to 30,000. $\mathrm{X}$ is the number of methylene groups in the main chain of HA, with a value between 1-4. $\mathrm{R}$ represents side-chain alkyl groups, which range from methyl $\left(\mathrm{C}_{1}\right)$ to tridecyl $\left(\mathrm{C}_{13}\right)$. In addition, the $\mathrm{R}$ groups can also be other branched-chain groups, such as halogenated, epoxide, aromatic, etc. [12].

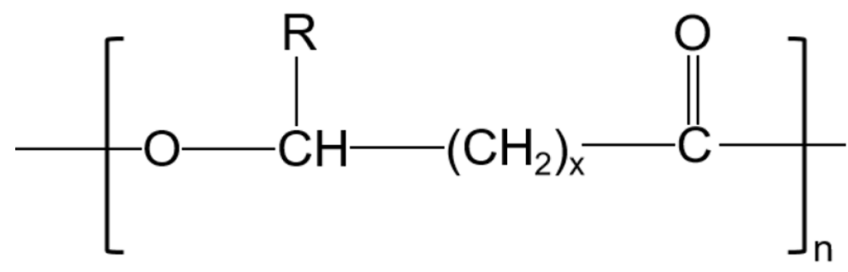

Fig. 1. The generic structural formula of PHA [12].
PHA can be divided into three types according to the number of carbon atoms in the monomer. Monomer with 2-5 carbon atoms is short-chain PHA(SCL-PHA), commonly includes PHB, polyhydroxyvalerate(PHV), and poly(hydroxybutyrate-co-hydroxyvalerate) (PHBV). PHBV is the copolymer of PHB and PHV. The carbon chain length with 6-14 carbon atoms is medium-chain PHA(MCL-PHA), such as $\mathrm{P}(\mathrm{HHx})$. And the short-chain and medium-chain PHA combine to form short-medium chain PHA(SCL-MCL-PHA), such as P(HB-co-HHX) [13]. Generally, SCL-PHA has high crystallinity and poor tensile strength, while MCL-PHA exhibits soft, elastic, and low crystallinity properties. Their combination, SCL-MCL-PHA, shows different elasticity and tensile strength according to the proportion of two monomer types in the copolymers [14]. Generally speaking, the larger amount monomers that make up PHA, the higher the molecular weight of PHA. The molecular weight of PHA typically ranges from 50,000 to 1 million Dalton, and it is widely thought that the higher the molecular weight, the tensile properties of the PHA expression come out [15].

The mechanical properties and processing properties of PHA are mainly affected by the components of the PHA monomer and the proportion of each component [16]. There are two most common HA monomer types in MMC-PHA production: hydroxybutyrate (HB) and hydroxyvalerate (HV) [17]. The PHA composed of only one kind of constituent is named homopolymer, such as PHB and PHV. While the PHA consisting of two or more constituents is a kind of copolymer, like PHBV. These three polymers are the most common and easy to produce PHA types in the MMC-PHA process. Homopolymer, like $\mathrm{PHB}$, has very strong hardness and water resistance due to its high crystallinity and high brittleness, but its low thermal stability is not conducive to ductile processing [18]. When a certain proportion of HV monomer is added to PHB, its ductility can be significantly enhanced. The higher the HV content, the stronger the toughness of its copolymer PHBV is, and the more effective it can improve the processing property of the polymer. PHBV showed a lower melting point, higher hardness, and better tensile property overall [19]. In addition, PHA with high HV content shows better water sensitivity and oxygen permeability [10, 20]. These studies conducted on the mechanical properties of PHA show that the proportion of $\mathrm{HB}$ and $\mathrm{HV}$ would affect the PHA-polymer final processing and mechanical properties, so we can synthesize PHA according to different processing requirements flexibly by regulating the monomer composition of PHA.

\section{The Conventional Process of MMC-PHA Production}

So far, the research reports on PHA synthesis by MMCs mostly focus on the research that used VFAs as carbon sources. Some studies used low-cost agricultural and industrial surplus raw materials or organic waste streams, such as fermented molasses, crude glycerol, etc., as carbon sources for MMC-PHA production [21]. But VFAs are the most preferred substrate in MMC-PHA production because VFAs are the precursors for PHA biosynthesis. The other substrates, like crude glycerol, tend to form glycogen instead of 


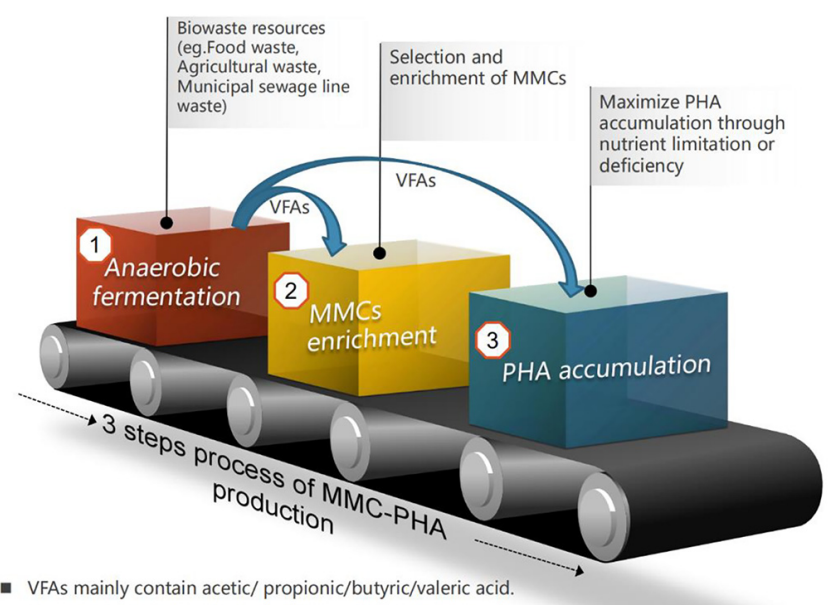

Fig. 2. Basic scheme with three steps of MMC-PHA production.

PHA [22]. So, the typical MMC-PHA production process obtains three steps (Fig. 2): (1) Anaerobic fermentation, in which the complex bio-waste resources are converted into VFAs through anaerobic fermentation; (2) MMCs enrichment, the dominant cultures with a good ability of PHA synthesis from activated sludge or other sources would be enriched in the condition of unbalanced nutritional condition. The main purpose of this stage is to screen out MMCs with PHA synthesis ability and then maximize enriching them. Therefore, this stage usually consists of two steps. Firstly, the bacteria with PHA synthesis ability will be screened out under the case of excessive carbon sources and the restriction of nitrogen and phosphorus. Then, under unrestricted conditions, the screened MMCs rapidly proliferate to a considerable concentration [23]. Generally speaking, PHA output will not be obtained at this stage. Because MMCs with PHA synthesis ability are screened and enriched through the cyclic process of "PHA synthesis, accumulation, and consumption" [24]. To obtain PHA output continuously, most of the biomass is extracted for PHA synthesis in the next stage, and the rest is left in the enrichment reactor to continue the enrichment cycle. (3) PHA accumulation, add VFAs produced from the first step into MMCs which have been enriched in the second step to accumulate the maximum amount of PHA and then recover it [1]. The main purpose of this stage is to obtain the maximum amount of PHA accumulation. In this stage, MMCs will have a small amount of proliferation (due to the limitation of nitrogen and phosphorus, the cytoplasmic synthesis of MMCs is limited). The main source of MMCs depends on the supply of Stage 2 [4].

\section{The Effect Factors on PHA Monomer Composition in MMC-PHA Production}

In pure culture, pure substrate and specific PHA-producing bacteria or transgenic engineering bacteria can be used to produce particular monomers. While the MMC-PHA production is a biological process that enriches the corresponding microbial population basing on natural ecological selection [25]. Therefore, based on the process development basis of ecological selection, it is a more practical method to produce specific PHA monomers by manipulating the process conditions in the MMC-PHA production process at the moment.

According to the previous studies, although MMCs contain different PHA-producing species, and each species of PHA-producing bacteria accumulates PHA with different molar mass and monomer composition distribution, some rules still can be found in the MMC-PHA production process. It can be observed from research that the types of microorganisms in MMCs and the composition of VFAs used as carbon source substrates greatly affect the PHA's monomer [1]. Most notably, one point should be emphasized that the VFAs composition plays a more vital role in regulating PHA monomer biosynthesis rather than the biodiversity of the MMC $[21,26]$. These two aspects will be reviewed and analyzed in the following part.

\subsection{Microbial Communities in MMC-PHA Production}

In MMC-PHA production, the most common biological carrier used for PHA production is MMCs in activated sludge. Since Wallen and Rohwedder discovered the stored PHA particles in the mixed bacterial community cells of activated sludge in 1974 [27], the metabolism of PHA in activated sludge has aroused the interest of wastewater treatment researchers, and the synthesis of PHA by mixed culture method was first applied to the phosphorus removal process in wastewater treatment [28]. To enhance the effect of biological phosphorus removal, researchers acclimated and enhanced the PHA synthesis and utilization capacity of phosphorus removal bacteria by different proportions of short-chain fatty acids [29-31]. With the progress of research, researchers have found that bacteria with PHA accumulation capacity in activated sludge can be divided into aerobic bacteria, phosphate accumulating organisms (PAOs), glycogen-accumulating organisms (GAOs) and filamentous bacteria [32]. Acinetobacter, Aeromonas, Pseudomonas in PAOs and Alcaligenes, Spirillum, Azotobacter and Pseudomonas in GAOs had strong PHB accumulation capacity [33]. The aerobic bacteria named plasticicumulans enriched from activated sludge by Johnson et al. can obtain PHA more than $80 \%$ of the cell dry weight in lab-scale [34], close to the production yield of pure culture. Some of these bacteria have the function of producing specific PHA. For example, Alcaligenes and Aeromonas are strains that can specifically produce SCL-PHA and PHHx in pure culture, respectively $[21,35,36]$. The reason for this phenomenon may be that there are specific PHA synthetases in the cells of the related bacterium. However, in the MMC-PHA production process, the completely open operating conditions easily make the synthetic PHA products unstable in nature and uneven in quality. Isolation and enrichment of specific bacteria from MMCs may be contrary to the original intention of the MMC-PHA production process. As a result, researchers prefer to enrich specific types of microbial communities by feeding specific types of VFAs substrates to MMCs to regulate the population metabolism and PHA synthesis quality of MMCs $[37,38]$. Therefore, in recent five years, a concept called 'Directed acid production (or oriented acid production)' has been developed, which is proposed in the background of regulating the production of specific PHA monomers [39-42]. More specifically, in the first stage of MMC-PHA synthesis, a particular proportion of VFAs was obtained employing operating parameters, operating conditions, screening of fermentation substrates and so on, then this kind 
of VFAs would be used as substrates for MMC-PHA synthesis, thus to obtain PHA with different monomer composition.

\subsection{The Association between MMC-PHA Production and Oriented Acid Production}

VFAs, the important intermediate product after the end of acid production and fermentation stage of organic matter anaerobic three-stage process, are considered as the preferred substrate for MMC-PHA production [43]. VFAs mainly refer to the short-chain fatty acids with less than six carbon atoms, and the common VFAs conclude acetic acid, propionic acid, valeric acid, and butyric acid. VFAs have a wide range of production sources, and they can be produced by anaerobic fermentation from the biowaste resources, for example, high-carbon wastewater (such as food industry wastewater, municipal landfill leachate, etc.), carbohydrate waste (i.e., biowaste resources rich in simple carbohydrates, such as glucose and sucrose) and so on [44]. According to the number of carbon atoms in the main chain, VFAs can be divided into odd carbon VFAs(OCFA) and even carbon VFAs(ECFA). OCFA generally refers to propionic acid, n-valeric acid and isovaleric acid, while ECFA refers to acetic acid, n-butyric acid and isobutyric acid.

In MMC-PHA fully open system, the VFAs-rich stream usually contains some sugar and protein, but according to the experimental report, the presence of sugar and protein does not affect the monomer composition of PHA [39]. The proportion of ECFA and OCFA in VFAs flow directly affects the monomer composition of PHA. Generally, the usage of ECFA in the MMC-PHA production process tends to generate HB monomer, whereas OCFA tends to yield $\mathrm{HV}$ and other longer-chain monomers, and researchers have been clearly identified this rule by employing sole VFA [4, 22, 42, 45].

The role of VFAs as substrates can be divided into two parts $[39,46]$. One is for the growth of MMCs, and the other is for the synthesis and storage of PHA. After VFA enters the cells through active transport under the consumption of adenosine triphosphate (ATP), and then be activated into acyl-CoA molecules(i.e. acetyl-CoA and propionyl-CoA, Fig. 3) through the $\beta$-oxidation pathway [47]. When the nitrogen and phosphorus in the substrate are limited, the tricarboxylic acid cycle (TCA) process would be delayed, limiting the biological process of bacterial synthesis of cytoplasm and genetic material, and leading to the slow growth rate of bacteria. As a result, the remaining acyl-CoA molecules that cannot be completely used in the TCA progress enter the PHA synthesis pathway [48]. In the PHA synthesis pathway, acetic acid and propionic acid can be directly activated to acetyl-CoA and propionyl-CoA, respectively. The rest of ECFA was converted to acetyl-CoA by the $\beta$-oxidative way, while OCFA was converted to crotonyl-CoA. The synthesis of PHB is the most widely studied and classic synthesis pathway of the MMC-PHA process. Firstly, 3-ketothiolase(PhaA) condenses two molecules of acetyl-CoA to form a molecule of acetoacetyl-CoA, and then acetoacetyl-CoA reductase( $\mathrm{PhaB})$ reduces it to 3-hydroxybutyrate-CoA, the precursor of $\mathrm{PHB}$, through $\mathrm{H}$ provided by NADPH. Finally, after the formation of the $\mathrm{HB}$ monomer, PHB synthase (PhaC) polymerizes the HB monomers, connects the bonds between monomers, and extends to form a biopolymer PHB. The synthesis process of PHV is similar to that of PHB, but the corresponding synthetases are slightly different [48]. In the PHV synthesis process, the HV monomer needs one molecule of acetyl-CoA and one molecule of crotonyl-CoA to be converted together [46].

In the first stage of the MMC-PHA process, controlling the composition of VFAs to obtain the particular PHA monomer synthesized is a macroscopic but effective method. It should be noted that oriented acid production does not refer to a specific type of acid but regulates the ratio of ECFA to OCFA in acid production to adapt to the percentage of PHB to PHV in PHA production[49].

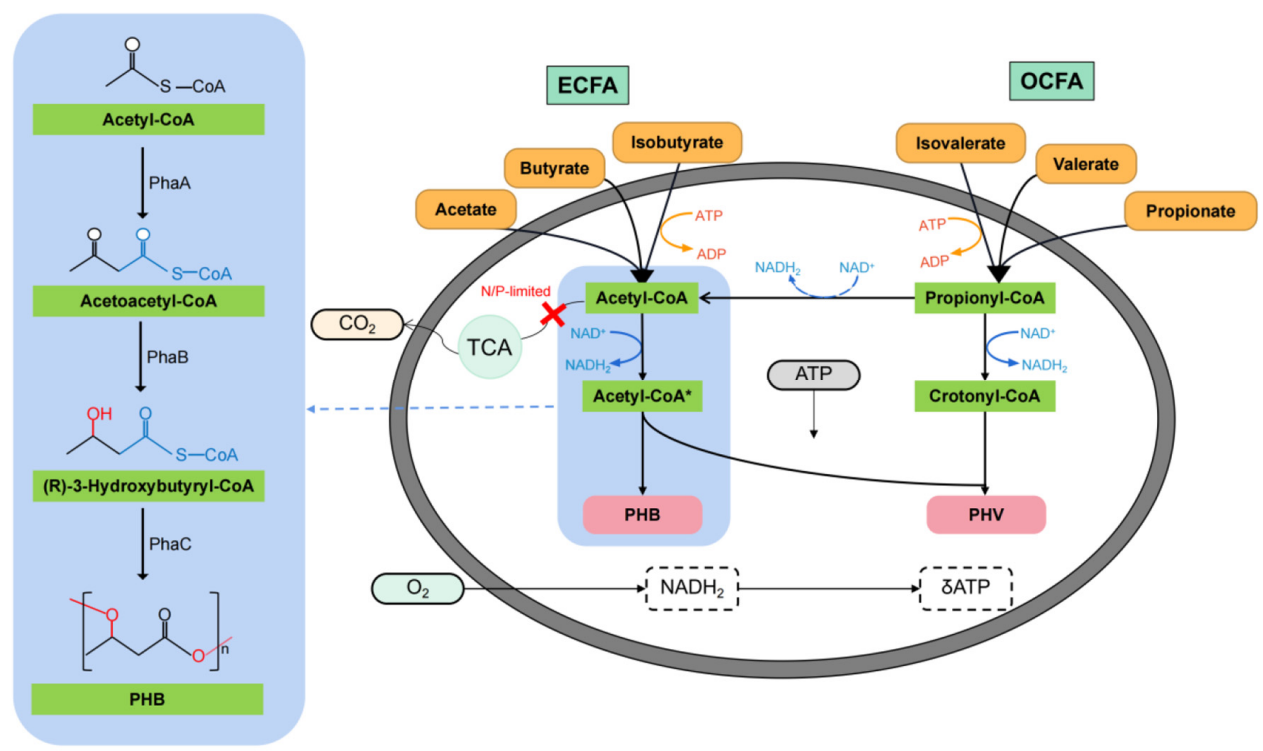

Fig. 3. Pathway of different VFAs in PHA synthesis [21, 46]. 


\section{Oriented Acid Production Progress}

A large number of works have been published on the production of VFAs from biowaste resources, and most of the research from laboratory scale to pilot scale is focused on the yield and utilization of VFAs [50-54]. The main research objects are the types of biowaste resources, the operation factors affecting acidification, and the microorganisms involved in acid production by fermentation [50, 55-58], while less attention is paid to the composition of VFAs under different operating conditions [59].

Before the concept of oriented acid production has been proposed in studies on VFAs, some factors (such as substrate type, operating characteristics, etc.) have been observed in many kinds of research that have a certain extent of influence on the VFAs composition and some rules can be found regularly [60-63]. Some studies also explored the possibility of selective production of VFAs under different conditions [64, 65], which provides an empirical basis for the oriented acid production by anaerobic fermentation of biowaste resources. The application scope was not only applied to the PHA synthesis[41]; in addition, it was also applied to increase the production of hydrogen and methane [66], and to enhance the effect of biological nitrogen removal(BNR) and enhanced biological phosphorus removal(EBPR) in wastewater treatment [67].

\subsection{Mechanisms for VFAs Production by Fermentation of Biowaste Resources}

As the valuable intermediate product produced by three-stage anaerobic fermentation of biowaste resources [43], VFAs mainly refer to short-chain volatile fatty acids composed of six or fewer carbon atoms. In the hydrolysis stage, acidogenic microorganism secretes extracellular hydrolases to decompose large molecules of organic matter into small molecules, a polysaccharide such as starch is decomposed into maltose and glucose by amylase, protein is hydro- lyzed into short peptides and amino acids by protease, and lipids are hydrolyzed into glycerol and long-chain fatty acid. After entering the acidogenic fermentation stage, the small molecular organic compounds produced in the hydrolysis stage are mainly converted to fatty acids as end products by acidogenic microorganisms, including formic acid, acetic acid, propionic acid, butyric acid, valeric acid, hexanoic acid and lactic acid [68], in which acetic acid, propionic acid, and butyric acid are the main VFAs products in the process of acid-producing fermentation [69] (Fig. 4), and they also form by-products such as ethanol and carbon dioxide [70].

Due to different types of microorganisms have different requirements on energy and internal redox balance, the substrate type, culture conditions, and microbial species all have significant influences on the components of VFAs produced in the process of acidogenic fermentation, thus different fermentation paths exist, and different fermentation products are formed. Zhou et al. [71] described the fermentation pathway of VFAs in detail. According to the types of organic acids produced during fermentation, fermentation is divided into acetic acid-ethanol type, propionic acid type, butyric acid type, mixed acid type, and lactic acid type metabolic pathways. It seems that different fermentation pathways determine the composition of VFAs, but in essence, the product spectrum of VFAs largely depends on the type of microorganism and the expression of key functional enzymes in vivo [68].

Since acetic acid and butyric acid are considered as the most common intermediates in the acid production process of biowaste resources [72], it is not difficult to find from previous studies that ECFA (acetic acid and butyric acid) usually accounts for a larger proportion in fermentation hydrolysates than OCFA (propionic acid and valeric acid), so most research experience focuses on ECFA-dominated hydrolysates [73, 74]. Therefore, the research object of oriented acid production is more inclined to increase the proportion of OCFA (propionic acid and valeric acid) in the total VFA produced.

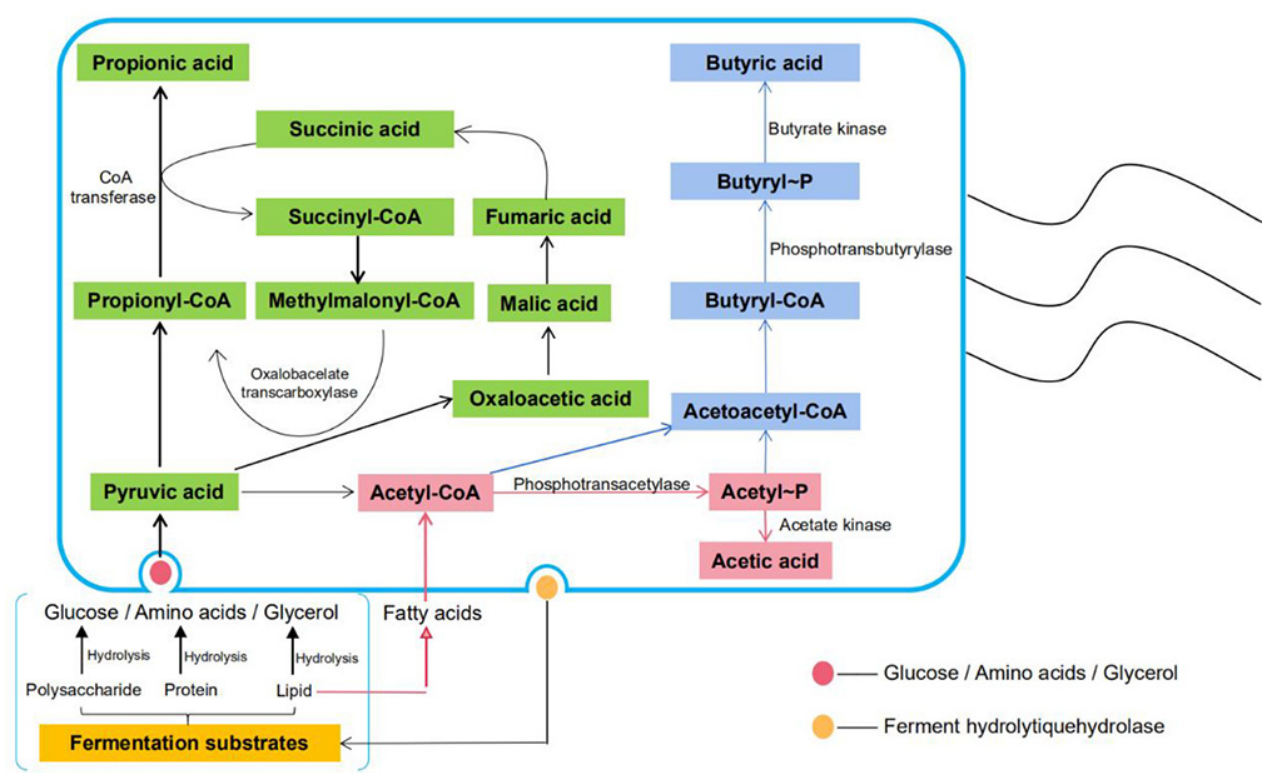

Fig. 4. The metabolic pathway for part of VFAs production [68]. 


\subsection{Impact Factors for Oriented Acid Production}

The concentration and component spectrum of VFAs results from different acidogenic metabolic pathways in acidogenic bacteria [71]. However, substrate characteristics, acidogenic bacteria involved in the reaction, and other operating conditions, such as $\mathrm{pH}$ and temperature, will greatly impact the acidogenic metabolic pathways, thus affecting the production and composition of VFAs [75]. In this paper, the influencing factors of VFAs components are sorted out from the following three aspects: substrate composition, acidogenic bacteria types and operating characteristics of acid fermentation ecological conditions.

\subsubsection{Types and composition of substrates}

Biowaste resources used for acid fermentation can be divided into agricultural and forestry waste, food waste and waste from food processing plants, high concentration wastewater and municipal sludge [50]. The composition can be divided into three kinds of biowaste resources rich in carbohydrates, protein, and triglycerides. Although it was mentioned above that ECFA is easier to be produced than OCFA, a regular pattern can be found from existing studies (Table 1 [75-79]: when the substrate is rich in lipids and proteins, OCFA (propionic acid and valeric acid) is more likely to obtain more output proportion of the total VFAs production [76, 77].

The effect of substrate types and composition on VFAs composition reflects the role of substrate specificity [80]. The above studies indicate that it is possible to produce OCFA by anaerobic fermentation with biowaste resources rich in lipid or glycerin. The chemical composition of proteins and lipids is likely to be the main reason to promote the output of OCFA. The free ammonium ion produced after proteins hydrolysis is conducive to promoting the content of COD in the substrate [81]. And the biowaste resources riching in fat contain a lot of oil and grease, and it can produce a lot of glycerine and high fatty acids after hydrolysis, and glycerol is an important precursor for the synthesis of propionic acid [82]. At the same time, oil can release a lot of heat energy during anaerobic decomposition to meet the Gibbs free energy required for propionic acid production by microorganisms. Meanwhile, a high concentration of higher fatty acids can significantly inhibit methanogens and acetic acid-producing bacteria [83], making the fermentation system to be more inclined to propionic acid fermentation. In addition, some scholars believe that glycerol is beneficial to propionic acid fermentation because of its high reducibility and can be oxidized to propionate ketone, thus producing more propionic acid to maintain the redox balance [84].

In other studies, by adding different kinds of waste to a single type of waste, changing the composition of the substrate can also achieve the purpose of changing the variety of fermentation products. Huang et al. [85] mixed peanut meal rich in protein with rice washing water rich in carbon to achieve propionic acid fermentation when $\mathrm{C} / \mathrm{N} \approx 56$. Ma et al. [86] found that the OCFA production could be improved by adding protein and lipids-rich waste, such as food waste to waste-activated sludge. Xiong et al. [87] added crude glycerol to the sludge for co-fermentation, which greatly increased the proportion of OCFA to total VFAs compared with the single sludge fermentation. This may be due to the high nitrogen content of sludge itself and the addition of crude glycerin is a carbon-rich substrate; by mixing the two in proportion, the $\mathrm{C} / \mathrm{N}$ ratio of the single substrate can be improved, which provides an appropriate nutritional balance for acidogenic bacteria, thus promoting the metabolic activities of acidogenic bacteria and enhancing the activities of key enzymes.

However, although some researchers believe that the composition of VFAs mainly depends on the design of substrates [68, 88], the composition and types of substrates are not decisive factors to determine the type of acid production. Substrate types may significantly affect the VFAs composition by affecting the metabolism of microorganisms and the evolution of the community structure of dominant bacteria. Therefore, from this point of view, the types of acidogenic bacteria and the physiological conditions of their growth may have a greater influence. Other studies have shown that the same substrate can have various fermentation types through pretreatment, fermentation conditions and other regulation. When exploring the impact of substrate components in oriented acid production progress on VFAs composition, it is necessary to systematically study and evaluate the coupling interactions among the substrate types, acidogenic bacteria and operating conditions in the acidogenic system.

\subsubsection{Types of acidogenic bacteria}

In general, biowaste resources can be hydrolyzed and produce acid by microorganisms existing in their system in the state of natural fermentation. These microorganisms can co-evolve into a relatively stable community under specific ecological conditions and produce corresponding VFAs. Most acidogenic microorganisms are anaerobes and some facultative anaerobes, and most of these bacteria belong to phylum Firmicutes. Previous studies showed that phylum Firmicutes can secrete extracellular enzymes related to the VFAs product such as lipid, protein, and polysaccharide hydrolysis [89]. This characteristic enables biowaste resources to be fully hydrolyzed and acidified.

As mentioned above, in the acid production mechanism, the

Table 1. Literature on the OCFA Production from Substrates Rich in Lipids and Proteins

\begin{tabular}{lcccc}
\hline Substrates types & Operating conditions & Total VFA yield & $\begin{array}{c}\text { Main OCFAs compositions of } \\
\text { total VFAs yield }\end{array}$ & Reference \\
\hline $\begin{array}{l}\text { Meat and bone meal } \\
\text { Crude glycerol }\end{array}$ & $\mathrm{pH}=10, \mathrm{~T}=55^{\circ} \mathrm{C}$ & $2,643 \mathrm{mgCOD} / \mathrm{L}$ & Isovaleric acid 27\% & {$[76]$} \\
$\begin{array}{l}\text { Grease, kitchen wastes } \\
\text { Hogwash waste grease }\end{array}$ & $\mathrm{pH}=4.4, \mathrm{~T}=35^{\circ} \mathrm{C}$ & $2,271 \mathrm{mgCOD} / \mathrm{L}$ & propionic acid $74 \%$ & propionic acid $32.2 \%$ \\
(drowning oil, waste meat and frying oil) & $\begin{array}{c}\text { Natural fermentation } \\
\text { in } 35^{\circ} \mathrm{C}\end{array}$ & $6,430.22 \mathrm{mg} / \mathrm{L}$ & propionic acid $54.73 \%$ & {$[78]$} \\
\hline
\end{tabular}


activities of key enzymes in different bacterial communities are various. That is, different bacterial communities have their metabolic characteristics and substrate preference, thus showing different metabolic pathways, namely under the different strains of type, pyruvate is converted into acetic acid, propionic acid, butyric acid, pentanoic acid opportunities is not the same [68]. In the acid-producing system, the common dominant flora is Proteobacteria, Scleroderma, and Bacteroidetes, in which genera were used as the dominant taxa, mainly including Bacteroides, Clostridium, Micrococcus, Streptococcus, Radiomycetes and Granulocytes [90]. As the executive body of VFAs production, exploring the evolution process of the community structure of acidogenic bacteria and classifying the dominant bacteria into ECFA producers and OCFA producers can reveal the interspecific relationship between different microbial communities and the correlation between microorganisms and acid production system, which will greatly benefit the future research on oriented acid production progress.

Huang et al. [41] found that the functional bacteria which can improve propionic acid yield include Proteococcus, Petrimonas, Clostridium, Lactococcus and Bacteroides. Among them, Proteococcus, Petrimonas and Clostridium are the producers that can directly use the substrate to generate propionic acid, and the rest are collaborators of auxiliary propionic acid production. Another researcher, Huang zhouyue [40], found that at the class level, $\gamma$-Proteobacteria dominated the output of OCFA, while $\alpha$ -Proteobacteria and $\beta$-Proteobacteria were closely related to the production of ECFA, and at the genus level, Veillonella, Acinetobacter and Pseudomonas have positive effects on OCFA production. Cibis et al. [90] isolated acetic acid, propionic acid and butyric acid-producing bacteria from biogas plants, and explored their growth characteristics (such as substrate utilization rate, substrate conversion, etc.), and obtained valuable information about the formation of acetic acid, propionic acid or butyric acid by conversion of important polymers and metabolites during organic matter degradation.

In addition, oriented acid production progress can be promoted by adding obligate strains when controlling the VFAs composition. After the initial fermentation of activated sludge and kitchen waste, Chen et al. [91] sterilized the original acid solution and inoculated Propionibacterium in the fermentation broth. As a result, the propionic acid content up to $7.13 \mathrm{~g} \mathrm{COD} / \mathrm{L}$, accounting for $68.4 \%$ of the total VFAs. It is worth noting that although inoculation with obligate strain can achieve the goal of oriented acid production, it is still necessary to evaluate further whether the use of pure bacteria inoculation of large-scale output to produce specific acid will offset the low-cost dividend brought by biowaste resources fermentation.

\subsubsection{Ecological conditions of the acid production process}

The ecological environment conditions (such as $\mathrm{pH}$, temperature, residence time, etc.) in the acid production system have an important impact on the composition of VFAs products (Table 2 [92-101]). In the acid production process, the ecological factors mainly affect the cell proliferation, growth, and metabolism of acidogenic bacteria by regulating the activity of key enzymes, which determines the VFAs composition [91].

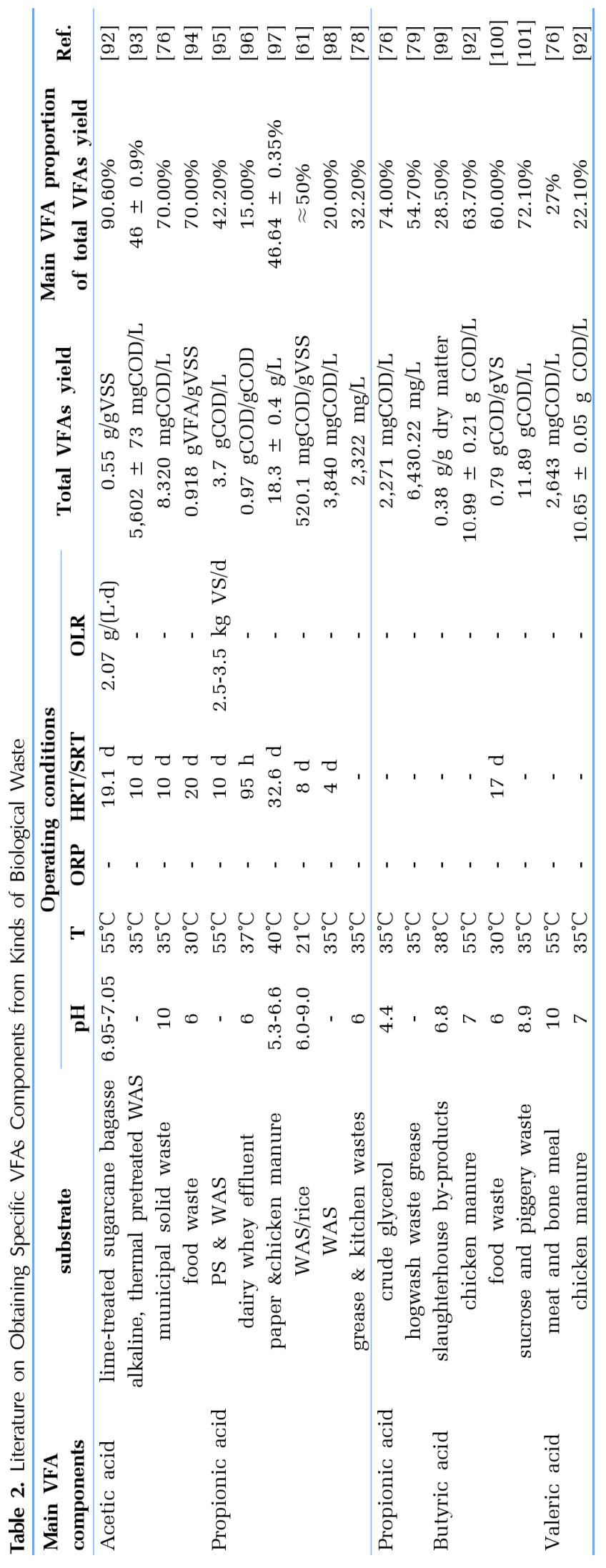




\subsubsection{1. $\mathrm{pH}$}

$\mathrm{PH}$ has an important impact on the key enzymes involved in acid production reactions in microorganisms. The too acidic or alkaline environment may lead to denaturation of enzyme proteins or affect their activity [102-104]. By affecting the activity of intracellular enzymes [105] or the metabolic balance of acidogenic bacteria [106], $\mathrm{pH}$ impacts the life and metabolism process of acidogenic bacteria. A suitable $\mathrm{pH}$ microenvironment can promote the growth of required acidogenic bacteria and meanwhile suppress the non-essential bacteria [107]. Therefore, each microorganism has its growth $\mathrm{pH}$ range. When the $\mathrm{pH}$ in the acid-producing reactor is close to the ecological requirements of some kind of acid-producing population, this kind of microorganism would become a dominant population through ecological competition, then affecting the types of VFAs produced. As a result, the VFAs composition may be changed when the range of $\mathrm{pH}$ in the acid production system changes. However, there are inconsistencies about the optimal range of $\mathrm{pH}$ values in the literature. Many researchers believed that a weakly acidic environment ( $\mathrm{pH}$ range 4-5) would be the best $\mathrm{pH}$ range for acetic acid production and that of butyric acid is 6-7 [108], while Farouk et al. [109] considered that both acetic acid and butyric acid can be effectively promoted under the $\mathrm{pH}$ range of 5-7. In contradiction, in other studies, alkaline conditions lead to an increase in the yield of acetic acid or butyric acid. For example, the acetic acid production in the acid-producing reactor of food waste reaches $91 \%$ at $\mathrm{pH}=9$ [81]. In another study, in the anaerobic conversion of sucrose and piggery waste, butyric acid was the main VFAs product at $\mathrm{pH}=8.9$ [101]. This indicates that the attainment of the desired VFAs component is not solely dependent on $\mathrm{pH}$, other parameters should also be considered when adjusted $\mathrm{pH}$ during acidogenic fermentation.

\subsubsection{Temperature}

Like $\mathrm{pH}$ value, temperature plays an important role in affecting the growth of acidogenic bacteria, the activities of key enzymes and the hydrolysis of particulate organic matter into soluble substances [110]. The metabolic rate of acid production process usually increases with the increase of temperature. From the thermodynamic perspective, in the suitable temperature range, the temperature rise is conducive to promoting the biowaste resources to release more carbohydrate and protein, and other nutrients, enhancing the enzyme activity of acidogenic bacteria to encourage the generation of specific VFA [111]. The growth rate and live metabolism of dominant bacteria are different under different temperature changes. It can be observed from the literature listed in Table 2 that medium and high temperature $\left(30-55^{\circ} \mathrm{C}\right)$ is the universal temperature range for VFAs production. However, the effect of temperature on obtaining the specific VFAs components during fermentation seems limited. Yuan et al. [111] found that when the fermentation temperature of waste-activated sludge increased from $4.0^{\circ} \mathrm{C}$ to $14.0^{\circ} \mathrm{C}$, the percentage of propionic acid in the total VFAs output increased only slightly from $20 \%$ to $29 \%$. In previously published studies, the contribution of temperature to the fermentation acid production process is more reflected in enhancing the total VFAs yield. But from another angle, adjusting the temperature combining with other fermentation factors can also be improved the output of required VFAs components in the acid production system. But remarkably, high-temperature treatment in large-scale production needs a lot of energy consumption, which may offset the benefits of the MMC-PHA production chain to a large extent.

\subsubsection{Oxidation-reduction potential (ORP)}

Due to the lack of an electron transport system in the anaerobic fermentation acid production system, a large amount of $\mathrm{NAD}^{+}$ is usually produced during substrate oxidative dehydrogenation. Therefore, $\mathrm{NAD}^{+} / \mathrm{NADH}$ has become a common redox pair in the intracellular metabolism of acid-producing bacteria [102]. ORP is the main index reflecting the electron transfer and redox balance of acidogenic bacteria in the reaction process [112]. However, information on the effect of ORP on the VFAs composition is still limited. Cohen et al. [113] have concluded that high ORP can lead to propionic acid fermentation. Ren et al. [102] proposed that when the ORP was low (ranges from -400 to $-200 \mathrm{mV}$ ), the ethanol type and butyric acid type fermentation often appeared, while it is easy to occur the propionic acid fermentation type when ORP ranges from -250 to $+100 \mathrm{mV}$. Zhao et al. [114] used waste molasses as fermentation substrate; by adjusting fermentation conditions $\mathrm{pH}$ and ORP, a similar conclusion was also obtained. Yin et al. [100] studied the effects of ORP and inoculation on VFAs production and found that ORP reached the maximum yield in the range of - 100 to - $200 \mathrm{mV}$. Information about how ORP affects specific VFA production still needs more researches.

\subsubsection{Substrate residence time and organic loading rate}

It is all known that acidogenic fermentation is a process based on the hydrolysis and acidogenic stages of anaerobic digestion. In acidogenic fermentation of complex biowaste resources, hydrolysis usually was identified as a rate-limiting step [115]. Ferrer et al. [95] studied the influence of SRT on the acid production of mixed sludge of primary sludge and residual sludge and found that propionic acid was the main VFAs component when SRT $=9.4$ days. As mentioned before, the substrate has an important influence on the composition of VFAs, the hydrolysis rate of substrates with different components is different, and at the same time, the growth rate of dominant flora that can produce specific types of VFAs is different. Therefore, the VFAs product spectrum is related to the residence time (containing sludge retention time (SRT) and hydraulic retention time (HRT)) to some extent. The studies of residence time will help to promote the development of oriented acid production.

The organic load rate (OLR) is a correlated parameter of HRT or SRT. It is reported that low OLRs can lead to the starvation of the cultures and thus stimulate the activity of microorganisms and accelerate the acid production process [116]. Li et al. [117] pointed out that when the OLR was at a high level, propionic acid was more easily obtained from the lactate-propionic acid pathway. This may be because when OLR is high, or HRT is low, more oxidizing compounds are converted to reducing compounds. Yu et al. [118] observed similar results at moderate temperatures: as OLR increased, the yield of propionic acid increased while the yield of acetic acid decreased. However, Jiang et al. [69] reported that under low OLR conditions, propionic and butyric acid production was facilitated, while the percentages of acetic and valerate in total VFAs increased with the increase of OLR. The underlying 
mechanism behind these observed phenomena remains to be further explored.

\subsubsection{Other factors}

In addition to the above factors, the researchers also studied other factors.

Kim et al. [119] found that the addition of trace elements positively affected VFAs composition. They added trace elements such as calcium, iron, nickel and cobalt in the thermophilic anaerobic sludge digestion system. The results showed that the addition of these trace elements contributed to the high concentration production of propionic acid.

As for additives, Yang et al. [120] pointed out that the addition of $\beta$-cyclodextrin ( $\beta$-CD) had no significant effect on the composition of VFA. However, Huang et al. [41] reported that when glycerol $(\mathrm{C} / \mathrm{N})$ was $15-20, \mathrm{pH}$ was $8.0-9.5$, and $\beta$ - $\mathrm{CD}$ was $0.2 \mathrm{~g} / \mathrm{gTss}$, they obtained more than $60 \%$ propionic acid.

Some researchers believe that the accumulation of VFAs in the acidogenic system would inhibit VFAs producing bacteria [69]. This principle is similar to that of reversible reaction: when a kind of VFA in the system accumulates to a certain extent, the production would be inhibited so that the formation of specific acid would be limited. Arslan et al. [121] selectively removed propionic acid from the acid production system by electrodialysis, thus doubling its productivity.

\subsubsection{Brief summary}

From the perspective of microbial community ecology, the interaction between the acidogenic bacterial community and its growth environment is an important factor affecting the VFAs composition, and the type of substrate also plays an important role. From the research mentioned above, we can find that due to the differences in working conditions and community structure in different acid production systems, the interaction of various influencing factors in the acid production system will obviously affect the product spectrum of VFAs. If only from a single influencing factor, the research on the same influencing factor may lead to inconsistent conclusions, proving the importance of synergistic effect between microorganisms and growth environment on VFAs components control. However, in the existing studies, more attention has been paid to the impact of operating parameters on VFAs product spectrum in the acid production system, which is only a surface phenomenon, and there is still a large blank space in the principle and mechanism behind these phenomena. In future research, revealing the mechanism of substrate, microorganism, and operating factors of the acid production system to control the formation of VFAs components will help provide a good theoretical basis for optimizing oriented acid production progress.

\subsection{Research Status of MMC-PHA Production Combined with Oriented Acid Production}

So far, the experience of MMC-PHA production combined with oriented acid production is still limited. In the current process report on the MMC-PHA production combined with oriented acid production, waste sludge is a common substrate for acid production (Table 3). The common feature of these processes is that the concentration of total organic matter and VFAs in the actual hydrolysate is very high. To improve the adaptability and stability of the MMC-PHA synthesis system, the hydrolysate needs to be pretreated (such as diluting [122] or removing the unnecessary nutrients [41] before adding to PHA biosynthetic reactor as substrate. Another method is to acclimate MMCs directly with hydrolysates with high VFAs concentration in the MMC enrichment stage. This way can help the MMCs fully adapt to the concentration of hydrolysate stock solution. Then in the subsequent phase, the PHA accumulation stage, the hydrolysate can be directly used as the substrate to maximize the accumulation of PHA without pretreatment [42].

In the future, developing efficient and low-cost VFAs pretreatment technology can be a good point. Meanwhile, the researches about economic analysis and life cycle assessment (LCA) on the

Table 3. Production Status of MMC-PHA Production Combined with Oriented Acid Production

\begin{tabular}{|c|c|c|c|c|c|c|c|}
\hline \multirow{2}{*}{$\begin{array}{l}\text { Feedstock for VFAs } \\
\text { production }\end{array}$} & \multirow{2}{*}{$\begin{array}{l}\text { Operating conditions in } \\
\text { VFAs production }\end{array}$} & \multirow[t]{2}{*}{ Total VFAs yield } & \multirow{2}{*}{$\begin{array}{l}\text { Main VFAs components } \\
\text { and proportion }\end{array}$} & \multirow{2}{*}{$\begin{array}{l}\text { PHA yield } \\
\text { (\%DCW) }\end{array}$} & \multicolumn{2}{|c|}{$\begin{array}{l}\text { PHA monomer } \\
\text { content(\%) }\end{array}$} & \multirow[t]{2}{*}{ Ref. } \\
\hline & & & & & PHB & PHV & \\
\hline $\begin{array}{l}\text { Papermaking } \\
\text { wastewater }\end{array}$ & $\begin{array}{c}\mathrm{pH}=6, \mathrm{~T}=30^{\circ} \mathrm{C} \\
\text { HRT }=16 \mathrm{~h}\end{array}$ & $\begin{array}{c}\approx 6,000 \mathrm{mg} \\
\quad \mathrm{COD} / \mathrm{L}\end{array}$ & propionic acid (40\%) & 48 & 47.00 & 53.00 & [122] \\
\hline $\begin{array}{l}\text { Co-ferment kitchen } \\
\text { waste and sludge }\end{array}$ & $\begin{array}{c}\mathrm{pH}=6.5, \mathrm{~T}=35^{\circ} \mathrm{C} \\
\mathrm{OLR}=4 \mathrm{gVSS} /(\mathrm{L} \cdot \mathrm{d}), \\
\text { SRT-8 d }\end{array}$ & $\begin{array}{c}\text { 18,062.66 mg } \\
\text { COD/L }\end{array}$ & $\mathrm{ECFA} / \mathrm{OCFA}=2.53$ & 47.65 & 79.00 & 21.00 & {$[63]$} \\
\hline excess sludge & $\begin{array}{c}\mathrm{pH}=6.8, \mathrm{~T}=55^{\circ} \mathrm{C} \\
\mathrm{SRT}=5 \mathrm{~d}\end{array}$ & $\begin{array}{l}5,947.50 \mathrm{mg} \\
\mathrm{COD} / \mathrm{L}\end{array}$ & valerate acid $(52.05 \%)$ & 42.31 & 68.40 & 23.70 & {$[42]$} \\
\hline WAS & $\begin{array}{c}\mathrm{pH}=8, \mathrm{~T}=35^{\circ} \mathrm{C} \\
\mathrm{SRT}=15 \mathrm{~d}, \mathrm{C} / \mathrm{N}=16 \\
\beta-\mathrm{CD}=0.1 \mathrm{~g} / \mathrm{gTSS}\end{array}$ & $\begin{array}{c}4,986 \pm 88 \mathrm{mg} \\
\mathrm{COD} / \mathrm{L}\end{array}$ & OCFA $=59.6 \pm 2.8 \%$ & $56.4 \pm 3.9$ & $\begin{array}{l}27.6 \\
\pm 0.8\end{array}$ & $\begin{array}{l}72.4 \\
\pm 5.2\end{array}$ & {$[41]$} \\
\hline WAS & $\begin{array}{c}\mathrm{pH}=9, \mathrm{~T}=36^{\circ} \mathrm{C} \\
\text { HRT }=24 \mathrm{~h}\end{array}$ & $\begin{array}{c}1,019 \pm 51.0 \mathrm{mg} \\
\mathrm{COD} / \mathrm{L}\end{array}$ & $\begin{array}{c}\text { Acetic acid (45.3\%) } \\
\text { Propionic acid (31.5\%) }\end{array}$ & 60.3 & 91.80 & 8.20 & [4] \\
\hline
\end{tabular}


MMC-PHA production combined with oriented acid production should also be encouraged.

\section{Conclusions}

In the process of MMC-PHA synthesis, it is one of the current research hotspots to obtain PHA products with different processing properties and mechanical properties by controlling the synthesized PHA monomer. In the laboratory scale, the control of VFAs as substrates can realize PHA monomers' specific production in MMCs. However, the oriented acid production process mechanism to achieve this goal has not been clear, and it still needs to be further explored. These research experiences will help to combine the three-stage process of MMC-PHA production more closely. Furthermore, the development of the oriented acid production process can undoubtedly promote the wide commercialization of MMC-PHA production.

\section{Acknowledgments}

This work was supported by the Natural Science Foundation of Guangdong Province (Grant no. 2017A030313273).

\section{Author Contributions}

T.W. (Master student) did writing and original draft preparation. Q.F. (Professor) did supervision, writing, reviewing and editing.

\section{References}

1. Sabapathy PC, Devaraj S, Meixner K, et al. Recent developments in Polyhydroxyalkanoates (PHAs) production - A review. Bioresour. Technol. 2020;306:123-132.

2. Zheng Y, Chen JC, Ma YM, Chen GQ. Engineering biosynthesis of polyhydroxyalkanoates (PHA) for diversity and cost reduction. Metab. Eng. 2020;58:82-93.

3. Singh M, Kumar P, Ray S, Kalia VC. Challenges and Opportunities for Customizing Polyhydroxyalkanoates. Indian J. Microbiol. 2015;55:235-249.

4. Liu Y, Guo L, Liao Q, et al. Polyhydroxyalkanoate (PHA) production with acid or alkali pretreated sludge acidogenic liquid as carbon source: Substrate metabolism and monomer composition. Process Saf. Environ. Prot. 2020;142:156-164.

5. Sudesh K, Abe H, Doi Y. Synthesis, structure and properties of polyhydroxyalkanoates: biological polyesters. Prog. Polym. Sci. 2000;25:1503-1555.

6. Lemoigne M. Produits de deshydration et de polymerisation de l'acide beta-oxybutyric. Finanz-Rundschau Ertragsteuerrecht. 1926;91:449-454.

7. Findlay RH, White DC. Polymeric Beta-Hydroxyalkanoates from Environmental Samples and Bacillus megaterium. Appl. Environ. Microbiol. 1983;45:71-78.

8. de Smet MJ, Eggink G, Witholt B, Kingma J, Wynberg H.
Characterization of intracellular inclusions formed by Pseudomonas oleovorans during growth on octane. J. Bacteriol. 1983;154:870-878.

9. Steinbüchel A, Valentin HE. Diversity of bacterial polyhydroxyalkanoic acids. FEMS Microbiol. Lett. 1995;128:219-228.

10. Zhang J, Shishatskaya EI, Volova TG, da Silva LF, Chen GQ. Polyhydroxyalkanoates (PHA) for therapeutic applications. Mater. Sci. Eng. C Mater. Biol. Appl. 2018;86:144-150.

11. Pagliano G, Ventorino V, Panico A, Pepe O. Integrated systems for biopolymers and bioenergy production from organic waste and by-products: a review of microbial processes. Biotechnol. Biofuels. 2017;10:113-137.

12. Tan D, Yin J, Chen GQ. Chapter 29: Production of Polyhydroxyalkanoates. In: Ashok P, Sangeeta N, Carlos RS, eds. Current Developments in Biotechnology and Bioengineering. Elsvier; 2017. p. 655-692.

13. Philip S, Keshavarz T, Roy I. Polyhydroxyalkanoates: Biodegradable polymers with a range of applications. J. Chem. Technol. Biotechnol. 2007;82:233-247.

14. Rai R, Keshavarz T, Roether JA, Boccaccini AR, Roy I. Medium chain length polyhydroxyalkanoates, promising new biomedical materials for the future. Mater. Sci. Eng. R Rep. 2011;72:29-47.

15. Luengo JM, García B, Sandoval A, Naharro G, Olivera EaR. Bioplastics from microorganisms. Curr. Opin. Microbiol. 2003;6:251-260.

16. Akaraonye E, Keshavarz T, Roy I. Production of polyhydroxyalkanoates: The future green materials of choice. $J$. Chem. Technol. Biotechnol. 2010;85:732-743.

17. Dias JML, Lemos PC, Serafim LS, et al. Recent Advances in Polyhydroxyalkanoate Production by Mixed Aerobic Cultures: From the Substrate to the Final Product. Macromol. Biosci. 2006;6:885-906

18. Bugnicourt E, Cinelli P, Alvarez V, Lazzeri A Polyhydroxyalkanoate (PHA): Review of synthesis, characteristics, processing and potential applications in packaging. EXPRESS Polymer Letters. 2014;8:791-808.

19. Poltronieri P, Kumar P. Polyhydroxyalkanoates (PHAs) in Industrial Applications. In: Leticia M, Torres M, Oxana VK, Boris IK, eds. Handbook of Ecomaterials. Cham: Springer; 2018. p. 1-30.

20. Martínez-Sanz M, Villano M, Oliveira C, et al. Characterization of polyhydroxyalkanoates synthesized from microbial mixed cultures and of their nanobiocomposites with bacterial cellulose nanowhiskers. N. Biotechnol. 2014;31:364-376.

21. Bhatia SK, Gurav R, Choi T-R, et al. Poly(3-hydroxybutyrate-co-3- hydroxyhexanoate) production from engineered Ralstonia eutropha using synthetic and anaerobically digested food waste derived volatile fatty acids. Int. J. Biol. Macromol. 2019;133:1-10.

22. Kourmentza C, Kornaros M. Biotransformation of volatile fatty acids to polyhydroxyalkanoates by employing mixed microbial consortia: The effect of $\mathrm{pH}$ and carbon source. Bioresour. Technol. 2016;222:388-398.

23. Frison N, Katsou E, Malamis S, Oehmen A, Fatone F. Development of a Novel Process Integrating the Treatment of Sludge Reject Water and the Production of Polyhydroxyalkanoates 
(PHAs). Environ. Sci. Technol. 2015;49:10877-10885.

24. Ling C, Qiao GQ, Shuai BW, et al. Engineering NADH/NAD(+) ratio in Halomonas bluephagenesis for enhanced production of polyhydroxyalkanoates (PHA). Metab. Eng. 2018;49:275-286.

25. Andreessen C, Steinbuchel A. Recent developments in non-biodegradable biopolymers: Precursors, production processes, and future perspectives. Appl. Microbiol. Biotechnol. 2019;103:143-157.

26. Koller M, Maršálek L, de Sousa Dias MM, Braunegg G. Producing microbial polyhydroxyalkanoate (PHA) biopolyesters in a sustainable manner. N. Biotechnol. 2017;37:24-38.

27. Wallen LL, Rohwedder WK. Poly- $\beta$-hydroxyalkanoate from activated sludge. Environ. Sci. Technol. 1974;8:576-579.

28. Satoh H, Iwamoto Y, Mino T, Matsuo T. Activated sludge as a possible source of biodegradable plastic. Water Sci. Technol. 1998;38:103-109.

29. Chen Y, Randall AA, McCue T. The efficiency of enhanced biological phosphorus removal from real wastewater affected by different ratios of acetic to propionic acid. Water Res. 2004;38:27-36.

30. Randall AA, Liu Y-H. Polyhydroxyalkanoates form potentially a key aspect of aerobic phosphorus uptake in enhanced biological phosphorus removal. Water Res. 2002;36:3473-3478.

31. Sato H, Mino T, Matsuo T. Uptake of Organic Substrates and Accumulation of Polyhydroxyalkanoates Linked with Glycolysis of Intracellular Carbohydrates under Anaerobic Conditions in the Biological Excess Phosphate Removal Processes. Water Sci. Technol. 1992;26:933-942.

32. Coats ER, Watson BS, Brinkman CK. Polyhydroxyalkanoate synthesis by mixed microbial consortia cultured on fermented dairy manure: Effect of aeration on process rates/yields and the associated microbial ecology. Water Res. 2016;106:26-40.

33. Ciesielski S. Determining Microbial Dynamics of Polyhydroxyalkanoates - Producing Consortium in Waste Glycerol using RISA Technique. In: $4^{\text {th }}$ International Conference on Environmental and Computer Science; 16-18 September 2011; Singapore.

34. Johnson K, Jiang Y, Kleerebezem R, Muyzer G, Loosdrecht MCMV. Enrichment of a Mixed Bacterial Culture with a High Polyhydroxyalkanoate Storage Capacity. Biomacromolecules 2009;670-676.

35. Lee SH, Oh DH, Ahn WS, Lee Y, Choi J, Lee SY. Production of poly(3-hydroxybutyrate-co-3-hydroxyhexanoate) by high-cell-density cultivation of Aeromonas hydrophila. Biotechnol. Bioeng. 2000;67:240-244.

36. Gahlawat G, Srivastava AK. Model-Based Nutrient Feeding Strategies for the Increased Production of Polyhydroxybutyrate (PHB) by Alcaligenes latus. Appl. Biochem. Biotechnol. 2017;183:530-542.

37. Luzi F, Torre L, Kenny JM, Puglia D. Bio- and Fossil-Based Polymeric Blends and Nanocomposites for Packaging: Structure -Property Relationship. Materials (Basel). 2019;12:471.

38. Khan MA, Ngo HH, Guo W, et al. Selective production of volatile fatty acids at different $\mathrm{pH}$ in an anaerobic membrane bioreactor. Bioresour. Technol. 2019;283:120-128.

39. Huang L, Chen Z, Wen Q, Ji Y, Wu Z, Lee DJ. Toward flexible regulation of polyhydroxyalkanoate composition based on substrate feeding strategy: Insights into microbial community and metabolic features. Bioresour. Technol. 2020;296:122369.

40. Huang Z. Process Optimization of the production of Odd-Carbon VFAs and Microbial community analysis from Hogwash waste grease dissertation. Guangzhou: Guangzhou University; 2019.

41. Huang L, Chen Z, Xiong D, Wen Q, Ji Y. Oriented acidification of wasted activated sludge (WAS) focused on odd-carbon volatile fatty acid (VFA): Regulation strategy and microbial community dynamics. Water Res. 2018;142:256-266.

42. Hao J, Wang X, Wang H. Overall process of using a valerate-dominant sludge hydrolysate to produce high-quality polyhydroxyalkanoates (PHA) in a mixed culture. Sci. Rep. 2017;7:6939.

43. Dahiya S, Sarkar O, Swamy YV, Venkata Mohan S. Acidogenic fermentation of food waste for volatile fatty acid production with co-generation of biohydrogen. Bioresour. Technol. 2015;182:103-113.

44. Cruz MV, Freitas F, Paiva A, et al. Valorization of fatty acids-containing wastes and byproducts into short- and medium-chain length polyhydroxyalkanoates. N. Biotechnol. 2016;33:206-215.

45. Albuquerque MGE, Martino V, Pollet E, Avérous L, Reis MAM. Mixed culture polyhydroxyalkanoate (PHA) production from volatile fatty acid (VFA)-rich streams: Effect of substrate composition and feeding regime on PHA productivity, composition and properties. J. Biotechnol. 2011;151:66-76.

46. Pardelha F, Albuquerque MG, Reis MA, Dias JM, Oliveira R. Flux balance analysis of mixed microbial cultures: application to the production of polyhydroxyalkanoates from complex mixtures of volatile fatty acids. J. Biotechnol. 2012;162:336-345.

47. Tu W, Zhang D, Wang H. Polyhydroxyalkanoates (PHA) production from fermented thermal-hydrolyzed sludge by mixed microbial cultures: The link between phosphorus and PHA yields. Waste Manag. 2019;96:149-157.

48. Możejko-Ciesielska J, Kiewisz R. Bacterial polyhydroxyalkanoates: Still fabulous? Microbiol. Res. 2016;192:271-282.

49. Jiang G, David H, Marek K, et al. Carbon Sources for Polyhydroxyalkanoates and an Integrated Biorefinery. Int. J. Mol. Sci. 2016;17:1157.

50. Lee WS, Chua ASM, Yeoh HK, Ngoh GC. A review of the production and applications of waste-derived volatile fatty acids. Chem. Eng. J. 2014;235:83-99.

51. Fortela DL, Hernandez R, French WT, et al. Extent of inhibition and utilization of volatile fatty acids as carbon sources for activated sludge microbial consortia dedicated for biodiesel production. Renew. Energy. 2016;96:11-19.

52. Atasoy M, Owusu-Agyeman I, Plaza E, Cetecioglu Z. Bio-based volatile fatty acid production and recovery from waste streams: Current status and future challenges. Bioresour. Technol. 2018;268:773-786.

53. Begum S, Anupoju GR, Sridhar S, Bhargava SK, Jegatheesan V, Eshtiaghi N. Evaluation of single and two stage anaerobic digestion of landfill leachate: Effect of $\mathrm{pH}$ and initial organic loading rate on volatile fatty acid (VFA) and biogas production. Bioresour. Technol. 2018;251:364-373.

54. Gao P, Guo L, Sun J, et al. Effect of alkyl polyglycosides on the performance of thermophilic bacteria pretreatment for saline waste sludge hydrolysis. Bioresour. Technol. 2020;296:122307.

55. Agler MT, Wrenn BA, Zinder SH, Angenent LT. Waste to bio- 
product conversion with undefined mixed cultures: the carboxylate platform. Trends Biotechnol. 2011;29:70-78.

56. Silva FC, Serafim LS, Nadais H, Arroja L, Capela I. Acidogenic Fermentation Towards Valorisation of Organic Waste Streams into Volatile Fatty Acids. Chem. Biochem. Eng. Q 2013;27:467-476.

57. Shen L, Hu H, Ji H, et al. Production of polyhydroxybutyrate-hydroxyvalerate) from waste organics by the two-stage process: Focus on the intermediate volatile fatty acids. Bioresour. Technol. 2014;166:194-200.

58. Wang Y, Zang B, Li G, Liu Y. Evaluation the anaerobic hydrolysis acidification stage of kitchen waste by $\mathrm{pH}$ regulation. Waste Manage. 2016;53:62-67.

59. Fang W, Zhang X, Zhang P, et al. Overview of key operation factors and strategies for improving fermentative volatile fatty acid production and product regulation from sewage sludge. J. Environ. Sci. 2020;87:93-111.

60. Cokgor EU, Oktay S, Tas DO, Zengin GE, Orhon D. Influence of $\mathrm{pH}$ and temperature on soluble substrate generation with primary sludge fermentation. Bioresour. Technol. 2009;100:380-386.

61. Feng L, Chen Y, Zheng X. Enhancement of waste activated sludge protein conversion and volatile fatty acids accumulation during waste activated sludge anaerobic fermentation by carbohydrate substrate addition: the effect of $\mathrm{pH}$. Environ. Sci. Technol. 2009;43:4373-4380.

62. Jankowska E, Chwiałkowska J, Stodolny M, Oleskowicz-Popiel P. Effect of $\mathrm{pH}$ and retention time on volatile fatty acids production during mixed culture fermentation. Bioresour. Technol. 2015;190:274-280.

63. Zhang M, Wu H, Chen $\mathrm{H}$. Coupling of polyhydroxyalkanoate production with volatile fatty acid from food wastes and excess sludge. Process Saf. Environ. Prot. 2014;92:171-178.

64. Horiuchi JI, Shimizu T, Tada K, Kanno T, Kobayashi M. Selective production of organic acids in anaerobic acid reactor by $\mathrm{pH}$ control. Bioresour. Technol. 2002;82:209-213.

65. Yang K, Yu Y, Hwang S. Selective optimization in thermophilic acidogenesis of cheese-whey wastewater to acetic and butyric acids: partial acidification and methanation. Water Res. 2003;37:2467-2477.

66. Kaur G, Johnravindar D, Wong JWC. Enhanced volatile fatty acid degradation and methane production efficiency by biochar addition in food waste-sludge co-digestion: A step towards increased organic loading efficiency in co-digestion. Bioresour. Technol. 2020;308:123-250.

67. Crutchik D, Frison N, Eusebi AL, Fatone F. Biorefinery of cellulosic primary sludge towards targeted Short Chain Fatty Acids, phosphorus and methane recovery. Water Res. 2018;136:112-119.

68. Chen Y, Luo J, Yan Y, Feng L. Enhanced production of short-chain fatty acid by co-fermentation of waste activated sludge and kitchen waste under alkaline conditions and its application to microbial fuel cells. ApEn. 2013;102:1197-1204.

69. Jiang J, Zhang Y, Li K, Wang Q, Gong C, Li M. Volatile fatty acids production from food waste: Effects of $\mathrm{pH}$, temperature, and organic loading rate. Bioresour. Technol. 2013;143:525-530.

70. Ghimire A, Frunzo L, Pirozzi F, et al. A review on dark fermentative biohydrogen production from organic biomass: Process parameters and use of by-products. ApEn. 2015;144:73-95.

71. Zhou M, Yan B, Wong JWC, Zhang Y. Enhanced volatile fatty acids production from anaerobic fermentation of food waste: A mini-review focusing on acidogenic metabolic pathways. Bioresour. Technol. 2018;248:68-78.

72. Eggeman T, Verser D. Recovery of organic acids from fermentation broths. Appl. Biochem. Biotechnol. 2005;122:605-618.

73. Jia S, Dai X, Zhang D, Dai L, Wang R, Zhao J. Improved bioproduction of short-chain fatty acids from waste activated sludge by perennial ryegrass addition. Water Res. 2013;47:4576-4584.

74. Wu L, Zhang C, Hu H, et al. Phosphorus and short-chain fatty acids recovery from waste activated sludge by anaerobic fermentation: Effect of acid or alkali pretreatment. Bioresour. Technol. 2017;240:192-196.

75. Riondet C, Cachon R, Waché Y, Alcaraz G, Diviès C. Extracellular oxidoreduction potential modifies carbon and electron flow in Escherichia coli. J. Bacteriol. 2000;182:620-626.

76. Garcia-Aguirre J, Aymerich E, Gonzalez-Mtnez de Goni J, Esteban-Gutierrez M. Selective VFA production potential from organic waste streams: Assessing temperature and $\mathrm{pH}$ influence. Bioresour. Technol. 2017;244:1081-1088.

77. Shen D, Yin J, Yu X, et al. Acidogenic fermentation characteristics of different types of protein-rich substrates in food waste to produce volatile fatty acids. Bioresour. Technol. 2017;227: 125-132.

78. Wang Q, Jiang J-g, Zhang H-w, Li M-l. Effect of grease on acid fermentation of kitchen waste by single phase anaerobic methods. China Environ. Sci. 2015;35:1436-1441.

79. Zeng Y, Fang Q, Huang Z, Huang D. Study on the performance of anaerobic fermentation of different kinds of hogwash waste grease. Appl. Chem. Ind. 2020;49:326-330.

80. Shin HS, Youn JH. Conversion of food waste into hydrogen by thermophilic acidogenesis. Biodegradation 2005;16:33-44.

81. Cheah Yen K, Vidal Antich C, Dosta J, Mata Álvarez J. Volatile fatty acid production from mesophilic acidogenic fermentation of organic fraction of municipal solid waste and food waste under acidic and alkaline pH. Environ. Sci. Pollut. Res. 2019;26:35509-35522.

82. Kosmider A, Drozdzynska A, Blaszka K, Leja K, Czaczyk K. Propionic Acid Production by Propionibacterium freudenreichii ssp. shermanii Using Crude Glycerol and Whey Lactose Industrial Wastes. Pol. J. Environ. Stud. 2010;19:12491253.

83. He Q, Dong B, Li J, Dai L, Dai X. Research Advances in the Inhibition of Long Chain Fatty Acid to Methanogenic Activity in Anaeroic Digestion System. Agric. Sci. Technol. 2012;13: 2389-2393.

84. Wang Z, Yang ST. Propionic acid production in glycerol/glucose co-fermentation by Propionibacterium freudenreichii subsp. shermanii. Bioresour. Technol. 2013;137:116-123.

85. Huang DW, Fang Q, Ji SM, Huang Zy, Zeng YY, Xiao YH. Synergistic effects of acid production by combined fermentation of peanut meal and rice washing water. Chinese J. Environ. Eng. 2019;13:465-473.

86. Ma H, Liu H, Zhang L, Yang M, Fu B, Liu H. Novel insight into the relationship between organic substrate composition and volatile fatty acids distribution in acidogenic co-fermentation. Biotechnol. Biofuels. 2017;10:137-152.

87. Xiong D. Research on process of direction acidsrugulation and 
PHA production using waste carbon resource dissertation. Heilongjiang: Harbin Institute of Technology; 2016.

88. Khan MA, Ngo HH, Guo WS, et al. Optimization of process parameters for production of volatile fatty acid, biohydrogen and methane from anaerobic digestion. Bioresour. Technol. 2016;219:738-748.

89. Chen Y, Jiang X, Xiao K, Shen N, Zeng RJ, Zhou Y. Enhanced volatile fatty acids (VFAs) production in a thermophilic fermenter with stepwise $\mathrm{pH}$ increase - Investigation on dissolved organic matter transformation and microbial community shift. Water Res. 2017;112:261-268.

90. Cibis KG, Gneipel A, König H. Isolation of acetic, propionic and butyric acid-forming bacteria from biogas plants. J. Biotechnol. 2016;220:51-63.

91. Chen Y, Li X, Zheng X, Wang D. Enhancement of propionic acid fraction in volatile fatty acids produced from sludge fermentation by the use of food waste and Propionibacterium acidipropionici. Water Res. 2013;47:615-622.

92. Fu Z, Holtzapple MT. Consolidated bioprocessing of sugarcane bagasse and chicken manure to ammonium carboxylates by a mixed culture of marine microorganisms. Bioresour. Technol. 2010;101:2825-2836.

93. Zhou A, Du J, Varrone C, Wang Y, Wang A, Liu W. VFAs bioproduction from waste activated sludge by coupling pretreatments with Agaricus bisporus substrates conditioning. Process Biochem. 2014;49:283-289.

94. Wang K, Yin J, Shen D, Li N. Anaerobic digestion of food waste for volatile fatty acids (VFAs) production with different types of inoculum: Effect of pH. Bioresour. Technol. 2014;161:395-401.

95. Ferrer I, Vázquez F, Font X. Long term operation of a thermophilic anaerobic reactor: Process stability and efficiency at decreasing sludge retention time. Bioresour. Technol. 2010;101: 2972-2980.

96. Bengtsson S, Hallquist J, Werker A, Welander T. Acidogenic fermentation of industrial wastewaters: Effects of chemostat retention time and $\mathrm{pH}$ on volatile fatty acids production. Biochem. Eng. J. 2008;40:492-499.

97. Golub KW, Smith AD, Hollister EB, Gentry TJ, Holtzapple MT. Investigation of intermittent air exposure on four-stage and one-stage anaerobic semi-continuous mixed-acid fermentations. Bioresour. Technol. 2011;102:5066-5075.

98. Zhou AJ, Yang CX, Guo ZC, Hou YA, Liu WZ, Wang AJ. Volatile fatty acids accumulation and rhamnolipid generation in situ from waste activated sludge fermentation stimulated by external rhamnolipid addition. Biochem. Eng. J. 2013;77:240-245.

99. Pessiot J, Nouaille R, Jobard M, et al. Fed-batch Anaerobic Valorization of Slaughterhouse By-products with Mesophilic Microbial Consortia Without Methane Production. Appl. Biochem. Biotechnol. 2012;167:1728-1743.

100. Yin J, Yu X, Zhang Y, et al. Enhancement of acidogenic fermentation for volatile fatty acid production from food waste: Effect of redox potential and inoculum. Bioresour. Technol. 2016;216:996-1003.

101. Choi J, Ahn Y. Biohydrogen Fermentation from Sucrose and Piggery Waste with High Levels of Bicarbonate Alkalinity. Energies 2015;8:1716-1729.

102. Ren N, Wang A, Ma F. Physiological Ecology of Acidogens in Anaerobic Biotreatment Process. 1st ed. Bei Jing: Science Press; 2005. p. 61-65.

103. Vongvichiankul C, Deebao J, Khongnakorn W. Relationship between pH, Oxidation Reduction Potential (ORP) and Biogas Production in Mesophilic Screw Anaerobic Digester. Energy Procedia. 2017;138:877-882.

104. Wang P, Ye M, Cui Y, et al. Enhancement of enzyme activities and VFA conversion by adding $\mathrm{Fe} / \mathrm{C}$ in two-phase high-solid digestion of food waste: Performance and microbial community structure. Bioresour. Technol. 2021;331:125004.

105. Mohd-Zaki Z, Bastidas-Oyanedel JR, Lu Y, et al. Influence of $\mathrm{pH}$ Regulation Mode in Glucose Fermentation on Product Selection and Process Stability. Microorganisms 2016;4:2-11.

106. Temudo MF, Kleerebezem R, van Loosdrecht M. Influence of the $\mathrm{pH}$ on (open) mixed culture fermentation of glucose: a chemostat study. Biotechnol. Bioeng. 2007;98:69-79.

107. Venkata Mohan S. Harnessing of biohydrogen from wastewater treatment using mixed fermentative consortia: Process evaluation towards optimization. Int. J. Hydrog. Energy. 2009;34: 7460-7474.

108. Hussain A, Filiatrault M, Guiot SR. Acidogenic digestion of food waste in a thermophilic leach bed reactor: Effect of $\mathrm{pH}$ and leachate recirculation rate on hydrolysis and volatile fatty acid production. Bioresour. Technol. 2017;245:1-9.

109. Yasser Farouk R, Li L, Wang Y, Li Y, Melak S. Influence of pretreatment and $\mathrm{pH}$ on the enhancement of hydrogen and volatile fatty acids production from food waste in the semi-continuously running reactor. Int. J. Hydrog. Energy. 2020;45:3729-3738.

110. Moser-Engeler R, Udert KM, Wild D, Siegrist H. Products from primary sludge fermentation and their suitability for nutrient removal. Water Sci. Technol. 1998;38:265-273.

111. Yuan Q, Sparling R, Oleszkiewicz JA. VFA generation from waste activated sludge: Effect of temperature and mixing. Chemosphere 2011;82:603-607.

112. Liu CG, Xue C, Lin YH, Bai FW. Redox potential control and applications in microaerobic and anaerobic fermentations. Biotechnol. Adv. 2013;31:257-265.

113. Cohen A, Jm V, Zoetemeyer R, Breure A. Main characteristics and stoichiometric aspects of acidogenesis of soluble carbohydrate containing wastewater. Process Biochem. 1984;19: 228-237.

114. Zhao D, Ren N, Wang A. Fermentation Type and Climax Community Controlled by pH, ORP. Chongqing Environ. Sci. 2003;25:33-38.

115. Feng Q, Song YC, Kim DH, Kim ms, Kim DH. Influence of the temperature and hydraulic retention time in bioelectrochemical anaerobic digestion of sewage sludge. Int. J. Hydrog. Energy. 2018;44:2170-2179.

116. Jankowska E, Duber A, Chwialkowska J, Stodolny M, Oleskowicz-Popiel P. Conversion of organic waste into volatile fatty acids - The influence of process operating parameters. Chem. Eng. J. 2018;345:395-403.

117. Li X, Zhang W, Ma L, et al. Improved production of propionic acid driven by hydrolyzed liquid containing high concentration of l-lactic acid from co-fermentation of food waste and sludge. Bioresour. Technol. 2016;220:523-529. 
118. Yu HQ, Fang HHP, Gu GW. Comparative performance of mesophilic and thermophilic acidogenic upflow reactors. Process Biochem. 2002;38:447-454.

119. Kim M, Ahn YH, Speece RE. Comparative process stability and efficiency of anaerobic digestion; mesophilic vs. thermophilic. Water Res. 2002;36:4369-4385.

120. Yang X, Du M, Lee DJ, et al. Enhanced production of volatile fatty acids (VFAs) from sewage sludge by $\beta$-cyclodextrin. Bioresour. Technol. 2012;110:688-691.
121. Arslan D, Zhang Y, Steinbusch KJJ, et al. In-situ carboxylate recovery and simultaneous $\mathrm{pH}$ control with tailor-configured bipolar membrane electrodialysis during continuous mixed culture fermentation. Sep. Purif. Technol. 2017;175:27-35.

122. Bengtsson S, Werker A, Christensson M, Welander T. Production of polyhydroxyalkanoates by activated sludge treating a paper mill wastewater. Bioresour. Technol. 2008;99:509-516. 